\title{
A EDUCAÇÃO INCLUSIVA NO MUNICÍPIO DE ITAPETINGA-BA: avanços e desafios de uma política em ação
}

\author{
Geovania Fagundes Ribas ${ }^{1}$ \\ Ennia Débora Passos Braga Pires² \\ Silvânia Brito Araújo 3
}

\section{RESUMO}

O presente artigo é parte de uma pesquisa realizada em 2018 que teve como objetivo geral analisar a implementação da Política Nacional de Educação Especial na Perspectiva da Educação Inclusiva (PNEEPEI) no município de Itapetinga-BA. Este estudo visa apresentar uma análise comparativa entre o que está posto no Plano Municipal de Educação (PME), acerca da educação inclusiva, e o que, de fato, tem acontecido no "chão da escola" do referido município. Compreendida como uma pesquisa de abordagem qualitativa de cunho sóciohistórico, contou com o aporte teórico e metodológico da Teoria Histórico Cultural de Vygotsky e do Materialismo Histórico Dialético. Os resultados sinalizaram alguns avanços, como: o aumento de $214 \%$ nas matrículas de alunos com deficiência, do ano de 2015 a 2018; a criação do Centro de Atendimento Educacional Especializado (CAEE) em 2017 e de cinco Salas de Recursos Multifuncionais em 2018. dentre outros. Entretanto, alguns desafios foram destacados, como: a formação dos professores, a ampliação do quadro de profissionais para o Atendimento Educacional Especializado e a montagem de novas salas de recursos multifuncionais, levando-nos à conclusão de que o município tem dado passos tímidos, porém expressivos, na efetivação da PNEEPEl, eles representam pequenas estratégias que precisam ser ampliadas para todas as escolas, a fim de que se transformem em espaços inclusivos.

Palavras-chave: Educação Inclusiva. Plano Municipal de Educação. PNEEPEl.

\footnotetext{
1 Mestre em Educação pela Universidade Estadual do Sudoeste da Bahia (UESB), Vitória da Conquista - BA - Brasil. Docente do Instituto Federal de Ciências e Tecnologia da Bahia, Campus Porto Seguro - BA. Orcid ID: http://orcid.org/0000-0001-8335-010-X. E-mail: geoeduca.ifba@gmail.com

2 Doutora em Educação pela Universidade Estadual de Campinas (UNICAMP). Docente Programa de Pós-Graduação em Educação (PPGED) da Universidade Estadual do Sudoeste da Bahia - (UESB), Vitória da Conquista - BA - Brasil. Orcid ID: http://orcid.org/0000-00033924-4996. E-mail: enniadebora@uesb.edu.br

${ }_{3}^{3}$ Mestre em Educação pela Universidade Estadual do Sudoeste da Bahia (UESB), Vitória da Conquista - BA - Brasil. Coordenadora Pedagógica da Educação Infantil do Núcleo Pedagógico do Município de Vitória da Conquista - BA. Orcid ID: http://orcid.org/0000-0002751 1-6257. E-mail: silbaraujo@yahoo.com.br
} 


\title{
INCLUSIVE EDUCATION IN ITAPETINGA-BA: advances and challenges of a
}

\author{
policy in action
}

\begin{abstract}
This article is part of a research conducted in 2018 that aimed to analyze the implementation of the National Policy on Special Education in Perspective of Inclusive Education (PNEEPEI) in Itapetinga-BA. The purpose of this study is to present a comparative analysis between what is Municipal Education Plan (PME), on inclusive education, and what, in fact, has happened in the school of the mentioned city. Understood as a qualitative approach of a historical partner, with the contribution of the Theory and Methodology of Vygotsky Cultural Historical Theory and Materialism Historical Dialectic. The results showed some advances, such as: an increase in $214 \%$ in the enrollment of students with disabilities, from the year 2015 to 2018; the creation of Specialized Educational Assistance Center (CAEE) in 2017 and five rooms of Multifunctional Resources in 2018, and others. However, some challenges were highlighted as: the training of teachers, the expansion of the professionals for the Specialized Educational Assistance and the assembly of new multifunctional resource rooms, leading us to the conclusion that the city has given shy but expressive steps in the implementation of PNEEPEl, they represent small strategies that need to be expanded to all schools, so that they can become inclusive spaces.
\end{abstract}

Keywords: Inclusive Education. Municipal Education Plan. PNEEPEl.

\section{LA EDUCACIÓN INCLUSIVA EN EL CONDADO DE ITAPETINGA-BA: avanzos y desafíos de una política en acción}

\section{RESUMEN}

El presente artículo es parte de una investigación realizada en 2018 que tuve cómo objetivo general analizar la implementación de la Política Nacional de Educación Especial en la perspectiva de la Educación inclusiva (PNEEPEI) en el condado de Itapetinga-Ba. Este estudio mira presentar un análisis comparativo entre lo que está puesto en el Plan Municipal de Educación (PME), acerca de la educación inclusiva, y lo que, por supuesto, tiene acontecido en el "suelo de la escuela" del referido condado. Comprendida como una investigación de abordaje cualitativo de sello socio histórico, ha contado con la contribución teórica y metodológica de la Teoría Histórico Cultural de Vygotsky y del Materialismo Histórico Dialéctico. Los resultados señalaran algunos avanzos, cómo: el aumento de $214 \%$ en las inscripciones de alumnos con discapacidad, de año de 2015 a la 2018; la creación del Centro de Cuidado Educativo Especializado (En portugués - CAEE) en 2017 y de cinco Habitaciones de Recursos Multifuncionales en 2018, entre otros. Sin embargo, algunos desafíos fueron destacados, cómo: la formación de los profesores, la ampliación de cuadro de profesionales para el Atendimiento Educativo Especializado y la montaje de nuevas habitaciones de recursos multifuncionales, llevándonos a la conclusión de que el condado tiene dado huellas tímidas, sino 
expresivas, en la efectividad de la PNEEPEl, ellos representan pequeñas estrategias que necesitan ser expandidas para todas las escuelas, a fin de que se transformen en espacios inclusivos.

Palabras clave: Educación Inclusiva. Plan Municipal de Educación. PNEEPEI.

\section{INTRODUÇÃO}

O debate sobre a Educação Inclusiva tem se intensificado nas últimas décadas, em decorrência das leis que buscam corrigir os equívocos cometidos com a educação das pessoas com deficiência. Muitos são os discursos gerados em torno da temática: alguns mais idealistas, por acreditarem que a inclusão já aconteceu pelo simples fato de muitos alunos estarem inseridos na escola regular; e outros mais realistas, por acreditarem que a escola sozinha não consegue promover a inclusão, visto que não tem dado conta de atender nem aos alunos ditos "normais", quanto mais aos alunos com deficiência (MANTOAN; PIETRO, 2006).

Crochik (2015, p. 51) vem dizer que a educação inclusiva é um movimento importante, mas tem seus limites indicados socialmente. Da mesma forma que não se pode negar sua importância, não se deve aceitála sem questionar esses limites, seria um "otimismo resignado em relação à verdadeira fonte de injustiça social: a desigualdade provocada socialmente e reproduzida pelos homens".

Essa divergência de opiniões só expressa a necessidade de uma visão mais aprofundada sobre a temática, uma visão que parta das experiências de inclusão/exclusão, a realidade concreta, para analisar a totalidade, que envolve não só concepções e posicionamentos sócio-políticos daqueles que elaboram as políticas públicas, mas também interesses internacionais expressos nas exigências do Banco Mundial para liberação de financiamentos para o país. Como confirma Kassar (2011, p. 42):

A Educação Especial nas últimas décadas tem ganhado contorno de política pública constituída por embates entre diversos setores da sociedade e das instâncias governamentais, afetada, muitas vezes, por determinações originariamente externas ao país. 
É preciso, pois, um olhar crítico-reflexivo para a situação atual que estamos vivendo. Comecemos por um questionamento que julgamos de muita relevância: como efetivar políticas de educação inclusiva num contexto educacional altamente excludente, no qual a educação é regida pela lógica neoliberal, a lógica do mercado?

Nesse contexto, torna-se importante analisar as contradições que envolvem os processos de efetivação das políticas de educação inclusiva e conhecer como ela está sendo implementada no âmbito municipal, quais ações estão promovendo a sua materialização e quais os desafios enfrentados pelos gestores e professores.

Dessa forma, este artigo tem como objetivo analisar como está se efetivando a Política Nacional de Educação Especial na Perspectiva da Educação Inclusiva (PNEEPEI) na Rede Municipal de Educação de Itapetinga-BA, identificando quais estratégias da Meta 04/ Plano Municipal de Educação (PME), referente à educação inclusiva, estão sendo efetivadas, bem como as estratégias que ainda não foram alcançadas, identificando os entraves e desafios que permeiam esse processo de efetivação.

Para o alcance dos objetivos propostos, foram realizadas entrevistas semiestruturadas, objetivando conhecer a realidade local a partir daqueles que instituem e praticam as políticas. A análise dos dados coletados foi realizada com base no materialismo histórico dialético.

\section{Percurso Metodológico}

Compreendida como uma pesquisa de abordagem qualitativa de cunho sócio-histórico, este estudo contou com o aporte teórico e metodológico da Teoria Histórico Cultural, que tem como expoente o psicólogo e teórico educacional Lev Semyonovich Vygotsky, cujos estudos denunciavam a segregação das crianças com deficiência, defendendo a inclusão das mesmas nas classes regulares de ensino, para, em contato direto com o meio social, através da mediação do professor, serem capazes de desenvolver suas potencialidades. 
Para Vygotsky, desenvolver uma pesquisa numa perspectiva sóciohistórica significa estudar o fenômeno em seu processo de mudança e essa é uma premissa do método dialético. Sendo assim, a perspectiva sóciohistórica torna-se particularmente importante para as pesquisas em educação, pois busca, além de descrever a ação educativa, em permanente movimento, explicá-la, num processo dialético, em que pesquisador e sujeitos transformam e são transformados pela realidade investigada.

Os dados foram coletados através de fontes documentais e entrevista semiestruturada dirigida a 16 profissionais da educação do município de Itapetinga, dentre eles: professores, gestores, secretário de educação e especialistas que trabalham no Centro de Atendimento Educacional Especializado (CAEE). Optamos pela utilização de pseudônimos para citar nossos entrevistados. Para a escolha dos pseudônimos, decidimos homenagear pessoas que foram exemplos de superação, mostrando que todos podem se desenvolver, independentemente de suas deficiências.

O método utilizado para embasar a análise das informações obtidas foi o Materialismo Histórico Dialético, cujas categorias de totalidade, práxis, contradição e mediação, possibilitaram a realização de um diagnóstico da situação municipal quanto aos processos inclusivos que estão sendo construídos, bem como uma análise crítica dos discursos ideológicos e contradições que permeiam a implementação das políticas de inclusão.

Segundo Saviani (2005, p. 17), "não é possível, portanto, compreender radicalmente a história da sociedade contemporânea e, consequentemente, a história da educação contemporânea sem se compreender o movimento do capital". Nesse sentido, analisar uma política educacional de forma isolada, sem inseri-la na totalidade das manifestações sociais que a envolvem, seria desenvolver um estudo vazio de criticidade.

Nessa abordagem, o estudo da PNEEPEI requer, para a apreensão da sua essência, ponderar a correlação de forças (interesses econômicos, políticos, ideológicos) que permeiam sua implementação, afinal, na 
definição de uma política pública quase sempre há conflitos e antagonismos de classe.

Desse modo, ancoramos-nos no Materialismo Histórico Dialético para estudar as políticas educacionais, a partir das propriedades: universalidade (a PNEEPEI); singularidade (a implementação da PNEEPEI no município de Itapetinga-BA) e particularidade (comparação entre o que está posto no PME referentes à Educação Inclusiva e o que acontece na prática).

\section{Itapetinga e sua busca por uma Educação Inclusiva}

A educação especial no município de Itapetinga teve início com a APAE (Associação de Pais e Amigos dos Excepcionais) há mais de 40 anos, quando uma das fundadoras, visando à educação e inclusão de seu filho com deficiência na sociedade, encabeçou uma luta para fundar a entidade no município. Durante anos, a APAE ofereceu 0 ensino especializado, além de oficinas de arte, dança, música e integração social dos alunos com deficiência.

Sobre a trajetória da educação especial oferecida nas classes regulares de ensino no período anterior à implantação da PNEEPEI (2008), não encontramos em nossas buscas registros de publicações sobre as ações desenvolvidas pela Secretaria Municipal de Educação, sequer nos foi disponibilizado documentos que permitam montar uma linha do tempo demonstrando tais ações.

Aprovado em 2015 e tendo sua primeira avaliação em 2017, o Plano Municipal de Educação (PME) traz em sua meta 04 (quatro) 21 (vinte e uma) estratégias para a efetivação da PNEEPEI. Nosso estudo se direcionou exclusivamente a esta meta, que prevê:

Universalizar, para a população de 4 (quatro) a 17 (dezessete) anos com deficiência, transtornos globais do desenvolvimento e altas habilidades ou superdotação, o acesso à educação básica e ao atendimento educacional especializado, preferencialmente na rede regular de ensino, com a garantia de sistema educacional inclusivo, de salas de recursos multifuncionais, classes, escolas ou serviços especializados, públicos ou conveniados (ITAPETINGA, 2015, p. 82). 
Faremos a seguir uma análise da situação do município em relação ao cumprimento das estratégias que compõem essa meta. Na medida em que apresentarmos os dados da Secretaria de Educação, traremos a visão dos profissionais responsáveis pelo Centro de Atendimento Educacional Especializado (CAEE), bem como a visão dos professores e gestores representantes das escolas com um número expressivo de crianças com deficiência, pois só dessa forma poderemos perceber as contradições existentes entre o que está posto no PME e o que tem acontecido, de fato, no "chão da escola".

\subsection{Entre o PME e o "chão da escola": mediações e contradições de uma política em construção}

No que concerne à educação inclusiva, o município de Itapetinga vem dando pequenos passos, desde a implantação da PNEEPEl, em 2008, em busca da efetivação da política, pois toda mudança empreendida no âmbito educacional perpassa por uma quebra de paradigmas, pela ruptura de velhas práticas e, acima de tudo, pela união de todos os envolvidos.

A primeira avaliação do PME aconteceu, como já citamos, em 2017, por uma equipe composta por representes da Secretaria Municipal de Educação e Cultura (SEMEC), professores, responsáveis pelo CAEE, professores representantes do Conselho Municipal de Educação, dentre outros. Após esse período, montou-se uma comissão que continua reunindose regularmente para novas avaliações. Com base em dados coletados na SEMEC, elaboramos O Quadro 1, com o intuito de apresentar uma visão sobre o cumprimento da Meta 4/PME. Para tanto, elegemos categorias de conteúdo e dividimos as 21 estratégias que compõem a meta em: totalmente cumpridas, parcialmente cumpridas e não cumpridas ainda. 
QUADRO 1 - Avaliação realizada pela SEMEC sobre a Meta 4/PME 2015

\begin{tabular}{|c|c|c|c|}
\hline \multirow{2}{*}{ CATEGORIAS } & \multicolumn{2}{|l|}{ ESTRATÉGIAS DA META 4 - EDUCAÇÃO ESPECIAL/ INCLUSIVA } \\
\cline { 2 - 4 } & $\begin{array}{c}\text { TOTALMENTE } \\
\text { CUMPRIDAS }\end{array}$ & $\begin{array}{c}\text { PARCIALMENTE } \\
\text { CUMPRIDAS }\end{array}$ & $\begin{array}{c}\text { NÃO CUMPRIDAS } \\
\text { AINDA }\end{array}$ \\
\hline Acesso e permanência & 4.1 & 4.6 & 4.2 \\
\hline AEE, salas de recursos multifuncionais & 4.8 & 4.3 & \\
e educação bilíngue & & 4.4 & \\
\hline Oferta de profissionais de apoio & 4.13 & 4.7 & 4.18 \\
\hline Formação de professores & 4.20 & & \\
\hline Acessibilidade Pedagógica & & 4.3 & \\
\hline Articulação com os setores público/ & 4.14 & & \\
privado / comunitário & 4.15 & & \\
\hline Parceria com a universidade & 4.17 & 4.16 & \\
(apoio, pesquisa e assessoria) & & & \\
\hline
\end{tabular}

Fonte: SEMEC Itapetinga, 2018 (Elaborado pelas Autoras).

O quadro aponta que $43 \%$ das estratégias (nove) foram totalmente cumpridas, $43 \%$ foram parcialmente cumpridas e apenas $14 \%$ das estratégias (três) não foram cumpridas ainda. Considera-se uma avaliação relativamente positiva, se for levado em conta que o tempo de vigência do plano é de dez anos. Cabe, portanto, analisar como essas estratégias estão sendo cumpridas e se o que a secretaria considera como "totalmente ou parcialmente" realizado coaduna com a opinião daqueles que estão diretamente ligados aos processos inclusivos: os professores.

\section{a) Acesso e permanência}

Até o ano de 2009 não havia registro de alunos com deficiência matriculados na rede municipal de ensino, apesar dos mesmos estarem inseridos nas classes regulares. A falta de laudos, avaliações psicodiagnósticas ou psicológicas dificultava a matrícula desses alunos na modalidade especial, apenas os alunos que frequentavam a APAE eram cadastrados. Tal lacuna impedia o envio de recursos do governo federal para o atendimento especializado desses alunos. 
O cumprimento da estratégia 4.1/PME vem resolver esse problema, pois a mesma prevê a declaração, no censo nacional das matrículas dos (as) estudantes da educação regular da rede pública que recebam atendimento educacional especializado complementar e suplementar, sem prejuízo do cômputo dessas matrículas na Educação Básica regular (ITAPETINGA, 2015).

No censo de 2017, já constam as matrículas da modalidade Educação Especial, conforme expresso no Quadro 2. Sua leitura nos permite perceber um aumento considerável nas matrículas da modalidade Educação Especial em relação a 2009.

QUADRO 2 - Matrículas da Educação Especial/Inclusiva no Município de Itapetinga, 2017

\begin{tabular}{|c|c|c|c|c|c|c|c|c|c|}
\hline \multirow{5}{*}{$\begin{array}{l}\text { MUNICÍPIO } \\
\text { ITAPETINGA }\end{array}$} & \multicolumn{9}{|c|}{ Matrícula inicial } \\
\hline & \multicolumn{8}{|c|}{$\begin{array}{c}\text { Educação Especial } \\
\text { (Alunos de Escolas Especiais, Classes Especiais e Incluídos) }\end{array}$} & \multirow{4}{*}{$\begin{array}{c}\text { EJA } \\
\begin{array}{c}\text { Ensino } \\
\text { Fundamenta }\end{array}\end{array}$} \\
\hline & \multicolumn{4}{|c|}{ Educação Infantil } & \multicolumn{4}{|c|}{ Ensino Fundamental } & \\
\hline & \multicolumn{2}{|c|}{ Creche } & \multicolumn{2}{|c|}{ Pré-escola } & \multicolumn{2}{|c|}{ Anos Iniciais } & \multicolumn{2}{|c|}{ Anos Finais } & \\
\hline & Parcial & Integral & Parcial & Integral & Parcial & Integral & Parcial & Integral & \\
\hline $\begin{array}{c}\text { Municipal } \\
\text { Urbana }\end{array}$ & 5 & 15 & 21 & 0 & 136 & 37 & 80 & 11 & 57 \\
\hline $\begin{array}{l}\text { Municipal } \\
\text { Rural }\end{array}$ & 0 & 0 & 0 & 0 & 8 & 0 & 0 & 0 & 1 \\
\hline TOTAL & 5 & 15 & 21 & 0 & 144 & 37 & 80 & 11 & 58 \\
\hline \multicolumn{10}{|c|}{ TOTAL: 371} \\
\hline
\end{tabular}

Fonte: MEC/INEP/DEED (Adaptado pelas autoras).

O levantamento dos alunos matriculados em 2018 foi concluído e lançado no censo, contudo, até o momento da pesquisa ainda não tinham sido publicadas as sinopses estatísticas no site do INEP. Porém, é possível reafirmar que o cumprimento da estratégia 4.1, bem como da estratégia 4.8/PME, que tratam do acesso e permanência, é real e pode ser aferido por meio da evolução de matrículas na Educação Especial/Inclusiva, conforme mostra o gráfico seguinte. 
GRÁFICO 1 - Evolução das matrículas da Educação Especial/Inclusiva no município de Itapetinga-BA (2015-2018)

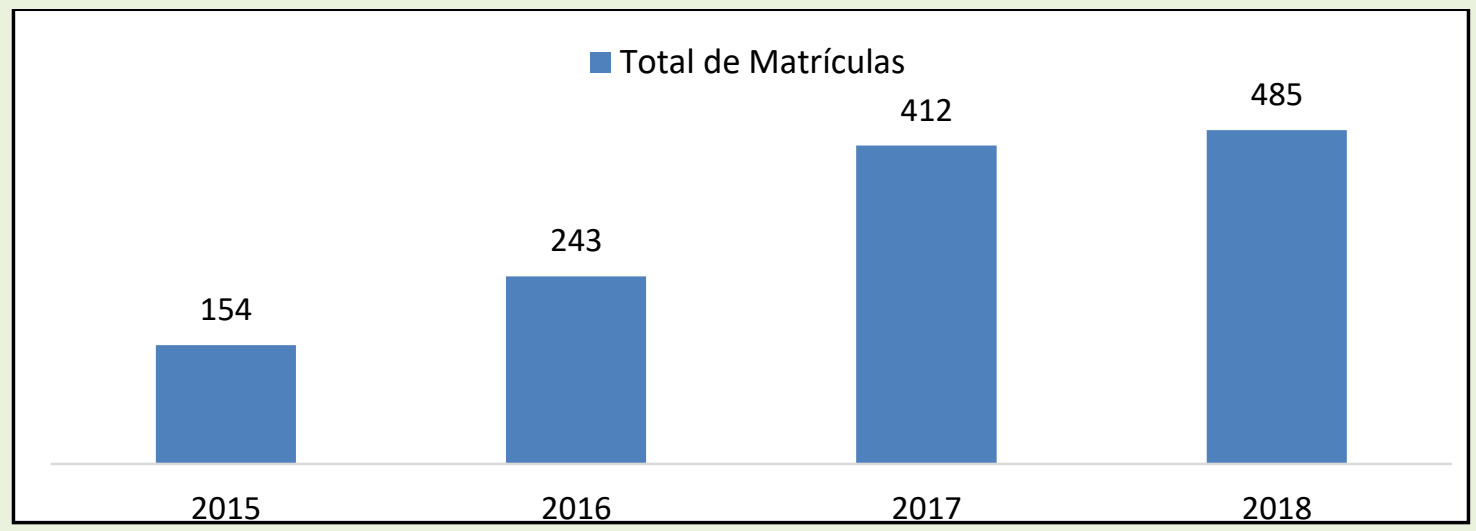

Fonte: INEP/Sinopses Estatísticas; SEMEC/ Censo Escolar, 2018.

Não obstante, ressalta-se que, além da garantia de acesso, é imprescindível a elaboração de ações que promovam a permanência desses alunos nas classes regulares. Isso porque o simples acesso não é garantia de que eles estão sendo atendidos em suas necessidades, ou seja, não é garantia de que eles saíram da condição de sujeitos "excluídos", construída historicamente, para a condição de cidadãos, cujo direito à aprendizagem é respeitado.

A preocupação em incluir todas as crianças com deficiência nas escolas regulares a qualquer custo, de qualquer jeito, sem um compromisso efetivo com seu atendimento especializado, "quando vista à luz dos interesses hegemônicos, é uma variante sociopolítica do reformismo inerente à pós-modernidade; um corretivo tipicamente marginal à lógica dominante, a fim de conservá-la, sem ameaçar sua integridade" (MESZAROS, 2008, apud BEZERRA, 2016 p. 70).

Com relação à estratégia 4.2/PME, que garante a universalização do atendimento escolar à demanda manifesta pelas famílias de crianças de 0 (zero) a 3 (três) anos com deficiência, a SEMEC reconhece que a mesma ainda não foi cumprida e justifica:

Ainda não há instrumentos pactuados para registro da demanda manifesta para esse público específico, contudo sabemos oficialmente que a demanda por creche não foi universalizada no município, em que pese os avanços (JOHN NASH, SECRETÁRIO DE EDUCAÇÃO). 
Mendes (2012) destaca que o atendimento ao público infantil tem sido o desafio das reformas educacionais em muitos países, essencialmente o atendimento educacional direcionado às crianças com deficiência. Uma das premissas desse atendimento, segundo a autora, é que quanto maior o tempo de privação da estimulação (visual, auditiva ou de movimento) mais permanente se torna a limitação da criança.

Tal entendimento pode ser explicado pela Teoria Histórico Cultural, quando trata dos processos de construção do pensamento da criança, sobretudo daquelas que apresentam as limitações oriundas da deficiência. Os estudos de Vygotsky (1998) afirmam que o desenvolvimento das funções psicológicas superiores ocorre desde o momento em que a criança nasce, porém evolvem qualitativamente durante os anos seguintes, conforme a sua interação com o ambiente social. Portanto, privada desta interação e sem a mediação de um profissional especializado, a criança, com ou sem deficiência, tem seu desenvolvimento comprometido.

Quanto à estratégia 4.6/PME, a SEMEC considera-a parcialmente cumprida. Ela prevê a ampliação da acessibilidade para garantir o acesso e a permanência dos (as) alunos (as) com deficiência por meio da adequação arquitetônica, da oferta de transporte, dentre outros [...] (ITAPETINGA, 2015). Julgamos que o município está "iniciando" os primeiros passos nesse sentido, pois apenas seis escolas foram contempladas com o Programa Escola Acessível num universo de 32 escolas. Quanto ao transporte acessível, este tem atendido à demanda do primeiro setor (escola), porém para O AEE, ainda não está sendo realizado, como esclarece a coordenadora do centro:

Tem o desafio do transporte para o AEE, que não pode ser só uma vez por semana, senão não reabilita as funções cognitivas. Ele tem acontecer pelo menos três vezes. Mas daí o pai diz não tem como trazer o filho porque não pode pagar transporte três vezes por semana. Alguns vêm andando, mas para outros fica distante. $O$ transporte da prefeitura não está vindo ainda porque não abriu o segundo setor, que é o do AEE (FRIDA KAHLO, COORDENADORA DO CAEE). 
Já a estratégia 4.9/PME, também considerada parcialmente cumprida, visa fortalecer o monitoramento do acesso à escola e ao AEE, bem como da permanência e dos alunos beneficiários (as) de programas de transferência de renda, juntamente com o combate às situações de discriminação, preconceito e violência [...] (ITAPETINGA, 2015). Uma ação da SEMEC nesse sentido foi firmar uma parceria com a Secretaria de Desenvolvimento Social, a fim de garantir a inserção dos alunos e suas famílias nos programas e benefícios socioassistenciais.

\section{b) Oferta de AEE, salas de recursos multifuncionais e educação bilíngue}

Buscando cumprir estratégia 4.4, que garante a oferta e o atendimento educacional especializado, a Secretaria de Educação de Itapetinga estrutura o Centro Educacional Especializado (CAEE). Assim, no dia 12 de dezembro de 2017 o CAEE é inaugurado, contando com uma equipe multidisciplinar, formada por: 01 (uma) psicopedagoga, 01 (uma) psicóloga, 01 (uma) pedagoga e psicóloga, 01 (um) educador físico, 01 (um) intérprete de LIBRAS e 01 (uma) pedagoga especializada em deficiência visual, um número bastante restrito, dado a demanda do município.

O CAEE centraliza, atualmente, todas as ações da SEMEC relacionadas à Educação Inclusiva, desde o AEE, que acontece no próprio centro, ao atendimento intinerante. Nesse local, os profissionais buscam, dentro das possibilidades, assistir às necessidades das escolas, no que se refere à avaliação psicodiagnóstica, assessoria nas adaptações curriculares, na construção de materiais e atividades pedagógicas. O depoimento de Frida Kahlo, psicóloga, pedagoga e coordenadora do CAEE, define com precisão as atividades desenvolvidas pelo centro:

\footnotetext{
"O carro chefe aqui é o atendimento especializado [...] Para o aluno que é cego, vamos adaptar tudo pra Braile, ensinar Braile; assim como o aluno que é surdo, ou tem perda auditiva, vamos ensinar LIBRAS e a Língua Portuguesa, ou seja, vamos criar instrumentos para minimizar suas barreiras diante do conhecimento; e os alunos com deficiência intelectual, a psicopedagoga faz todo um trabalho com materiais diferentes, ou seja, atividades que trabalham habilidades preditoras de leitura e de cálculo" (FRIDA KAHLO, COORDENADORA DO CAEE).
} 
Para todos os professores e gestores entrevistados, O CAEE representa um avanço para a educação inclusiva no município, porém, destacam as suas limitações e alertam para a necessidade do AEE ser oferecido nas escolas em que os alunos estão matriculados, em salas de recursos multifuncionais, tendo todos os recursos materiais e humanos necessários.

Com o intuito conhecer outra visão, que não a dos responsáveis pelo CAEE, elaboramos uma enquete que foi direcionada apenas aos professores e gestores das escolas (dez ao todo). Os entrevistados deveriam avaliar a atuação do Centro e os conceitos deveriam variar entre: insuficiente, regular, bom ou excelente. Seguem os resultados:

QUADRO 3: Visão dos professores e gestores sobre a atuação do CAEE

\begin{tabular}{|c|c|c|c|c|c|}
\hline \multirow{2}{*}{$\begin{array}{c}\text { ASPECTOS } \\
\text { OBSERVADOS }\end{array}$} & \multicolumn{5}{|c|}{ NÚMERO DE RESPOSTAS POR CONCEITO } \\
\cline { 2 - 6 } & INSUFICIENTE & REGULAR & BOM & EXCELENTE & S/R \\
\hline $\begin{array}{c}\text { Atendimento } \\
\text { Especializado }\end{array}$ & $60 \%$ & $10 \%$ & $10 \%$ & $20 \%$ & 0 \\
\hline $\begin{array}{c}\text { Encaminhamento de } \\
\text { Exames }\end{array}$ & $20 \%$ & $20 \%$ & $40 \%$ & 0 & $20 \%$ \\
\hline $\begin{array}{c}\text { Avaliação } \\
\text { Psicodiagnóstica }\end{array}$ & $30 \%$ & $60 \%$ & $10 \%$ & 0 & 0 \\
\hline Suporte Pedagógico & $40 \%$ & $40 \%$ & $20 \%$ & 0 & 0 \\
\hline
\end{tabular}

Fonte: Entrevistas.

Quanto ao atendimento especializado, vale ressaltar que os $60 \%$ dos profissionais que avaliaram como insuficiente não questionam a competência dos profissionais que atuam no centro, ou seja, a qualidade do atendimento não é insuficiente, mas estão se referindo à quantidade. As falas a seguir confirmam:

O atendimento do CAEE é de excelência, porém o número de profissionais para atender a demanda da rede ainda é insuficiente. Muitos alunos não são contemplados (CAROLINA TANAKA MENEGHEL, PROFESSORA).

Sei que os profissionais que atuam no CAEE são muito competentes. Contudo, o número é insuficiente para atender toda a rede. 
Encaminhei alguns alunos no início do ano e tive conhecimento que um deles foi atendido agora no final do ano (OLGA IVANOVNA, PROFESSORA).

Os dois profissionais (20\%) que avaliaram como excelente, ressaltaram que o atendimento é excelente, porém insuficiente. Destaca-se aqui uma afirmação de Cortella (1988, p. 14), citada por Prieto (2006, p. 45): "em uma democracia plena, quantidade é sinal de qualidade social e, se não tem quantidade total atendida, não se pode falar em qualidade". É necessário, portanto, estar atento às contradições existentes no âmago deste ideário inclusivista de educação, o qual se apresenta em forma de avanço, mas mantém a mesma base material capitalista (BEZERRA, 2016).

Quanto ao encaminhamento de exames, $20 \%$ dos entrevistados disseram não ter conhecimento; os $20 \%$ que avaliaram como insuficiente não justificaram o conceito; os $40 \%$ que avaliaram como bom e os $20 \%$ como regular, afirmam que a organização do CAEE promoveu uma melhora na parceria intersetorial com a saúde, embora ainda falte agilidade por parte deste setor, algo comum em se tratando de saúde pública no Brasil.

O CAEE agiliza os encaminhamentos, porém, como os exames são feitos pelo SUS a demora é grande. Aqui nós temos cinco alunos com autismo, apenas dois com laudo. Um deles foi diagnosticado logo, porque fez os exames pelo plano de saúde.

Os outros três ainda não conseguiram os exames. E olha que eu estou falando só dos autistas, temos várias outras crianças com necessidades diferentes (LAURA BRIDGMAN, PROFESSORA DE AEE).

Essa questão dos exames é bem complexa e pode realmente atrapalhar o avanço no processo de aprendizagem, como é o caso dos alunos com baixa visão, que necessitam do laudo médico indicando o nível de comprometimento para que o professor saiba quais adaptações devem ser feitas. Muitas vezes a escola sinaliza a necessidade dos exames logo no início do ano, mas nem sempre eles acontecem a contento.

Segundo a Secretaria de Educação, a estratégia 4.21, que trata das parcerias com instituições públicas e/ou privadas para realização anual de teste de acuidade visual com alunos da Rede Municipal (ITAPETINGA, 2015), foi totalmente cumprida em 2018. 
Em face às considerações apresentadas, reportamos-nos a Caiado e Laplane (2009) para trazer à discussão a relação existente entre deficiência, pobreza e educação no cenário brasileiro. As autoras destacam que, na área da deficiência, as políticas públicas se apresentam em três fases: a tradicional-caritativa, a de reabilitação e a da autonomia pessoal. Segundo essas autoras, dados do censo de 2000 revelam que:

a maioria das pessoas com deficiência no Brasil vive, ainda hoje, da caridade e da assistência, porque não tem renda e nem acesso aos serviços e bens públicos que garantem a dignidade da vida. [...] verifica-se que dentre as pessoas com deficiências consideradas como limitações mais severas, o percentual de indivíduos sem instrução é de $42,5 \%$, enquanto para o grupo sem deficiência é de 24,5\%. [...] pobreza e deficiência se entrelaçam nas regiões mais pobres e miseráveis do país (CAIADO; LAPLANE, 2009, p. 80).

Obviamente o censo está se referindo aos alunos com deficiência que necessitam da "caridade" alheia para conseguirem exames, óculos, cadeiras de roda, etc. É necessária, então, uma atenção maior a essas parcerias com os setores da saúde e de assistência social.

Quanto à avaliação psicodiagnóstica, $60 \%$ dos entrevistados avaliam como regular, $30 \%$ como insuficiente e 10\% consideram boa. Aqui os argumentos são basicamente os mesmos do atendimento especializado: não se questiona a qualidade dos diagnósticos, porém o número reduzido de profissionais para realizá-los, gerando atraso nas devolutivas, que nem sempre chegam a contento.

Avalio como regular. Sempre recebi devolutiva (normalmente oral), porque sempre estou cobrando. Sinto falta da devolução escrita/ documentada. Considero o documento importante, porque assim posso dar uma devolutiva consistente ao professor e com ele traçar um plano de trabalho para 0 aluno (EMANUELLE LABORIT, PROFESSORA, ATUA HOJE COMO COORDENADORA PEDAGÓGICA).

Assim que os professores percebem algo na criança e sinalizam pra gente, acionamos o CAEE para a avaliação psicodiagnóstica. A devolutiva vem, demora um pouco e não vem em forma de relatório escrito, é dada de forma oral. Precisamos de algo mais concreto para passar para os pais. Porém, entendemos que são poucos profissionais para a demanda da rede e eles ainda estão se organizando (CÁTIA OLIVEIRA, PROFESSORA, ATUA HOJE COMO COORDENADORA PEDAGÓGICA). 
As declarações acima revelam o grau de insatisfação dos professores quanto às avaliações psicodiagnósticas desenvolvidas pelo CAEE, apesar de reconhecerem o esforço dos profissionais que trabalham lá. Mais uma vez destacam que o número insuficiente de profissionais prejudica a qualidade do atendimento (atrasos nas devolutivas, falta de relatórios escritos) e o andamento do trabalho desenvolvido pela escola.

A inferência que extraímos dessas considerações é a avaliação psicodiagnóstica influencia a ação pedagógica e esta, por sua vez, o sucesso ou fracasso do processo de aprendizagem da criança com deficiência. Portanto, ela deve ser criteriosa, documentada e chegar às mãos do professor a tempo de se fazer um planejamento adequado às especificidades de cada aluno.

A falta de um diagnóstico preciso traz consequências para a intervenção pedagógica. Cerezuela (2016) chama atenção para as contradições que a inclusão e a sociedade inclusiva trazem em seu bojo. Na perspectiva da autora, o que estamos vivenciando é um deslocamento da responsabilidade coletiva (social) para a individual (orgânica), a fim de justificar, "através da biologização do desempenho", a não aprendizagem daqueles que fogem aos padrões de competência exigidos pelo mercado.

É preciso, pois, um olhar crítico/dialético sobre as contradições da prática educacional: as avaliações externas comprovam que os índices de desempenho dos nossos alunos são baixíssimos, trazendo à superfície problemas graves de leitura, escrita e lógica matemática que impedem o desenvolvimento não só de alunos, cuja deficiência é evidenciada, mas também, daqueles que trazem em sua história as marcas da exclusão social.

Quanto ao suporte pedagógico dado aos professores, as reclamações são muitas, $40 \%$ considera insuficiente e $40 \%$ regular. Todos atribuem a ineficiência ao número reduzido de profissionais do CAEE. Até os $20 \%$ que avaliam como bom asseveram que poderia ser bem melhor se houvesse um número maior de profissionais. 
que no início a psicopedagoga vinha de vez em quando e dava algumas orientações, mas, uma profissional só para tantas escolas... hoje temos uma professora de AEE e ela recebe esse suporte, não como deveria, mas tem. Porém, os outros professores não recebem e eles têm alunos com deficiência em suas salas (CÁTIA OLIVEIRA, PROFESSORA, ATUA HOJE COMO COORDENADORA PEDAGÓGICA).

Observa-se, com base nos relatos apresentados, que os professores não estão satisfeitos com a qualidade do serviço prestado pelo CAEE. Mesmo acreditando que o Centro representa um avanço e um passo importante na implementação da PNEEPEI, reconhecem suas lacunas. Até o momento, só os professores de AEE estão recebendo orientações, e estas não são constantes, são pontuais. Os demais professores estão caminhando sozinhos (são eles que passam a maior parte do tempo com as crianças) e ainda se sentem culpados por não estarem desenvolvendo o trabalho da forma que gostariam.

Marx usa o termo alienação para descrever a falta de conhecimento do trabalhador em relação ao valor do seu trabalho. O professor, mesmo se sentindo despreparado e sem apoio por parte do poder público, abstrai para si (classe docente) a responsabilidade pela inclusão dos alunos com deficiência. Concordamos, dessa maneira, com Saviani quando afirma: "[...] acreditar que estão dadas, nesta sociedade, as condições para o exercício pleno da prática educativa é assumir uma atitude idealista" (SAVIANI, 2009, p. 77 apud BEZERRA, 2016, p. 74).

Avançando para estratégia 4.3/PME, a qual prevê implantar, ao longo da vigência do plano, salas de recursos multifuncionais e fomentar a formação continuada de professores e professoras para $O$ atendimento educacional especializado nas escolas urbanas e do campo. A SEMEC considera essa estratégia parcialmente cumprida. Todavia, há um longo caminho pela frente.

No início da nossa pesquisa não havia salas de recursos multifuncionais (funcionando) em nenhuma escola, apesar do MEC ter enviado material para montagem de 05 (cinco) salas, em 2009. Todas ficaram inativas, tendo alguns materiais desviados indevidamente para outras atividades. Ao serem 
questionados sobre a existência dessas salas, os representantes da SEMEC (atual e da gestão anterior) sinalizaram:

Quando assumimos a gestão encontramos os equipamentos e mobiliários encaixotados. Desde então temos envidado esforços para garantir o uso dos mesmos através da criação de salas de AEE (JOHN NASH, SECRETÁRIO DE EDUCAÇÃO).

A secretária, na época, ainda tentou tirar essas salas de recursos e trazer para as escolas do projeto piloto, mas o MEC não permitiu que elas fossem mobilizadas de uma escola para outra. Tinha havido um roubo em uma das escolas, levaram um notebook e uma máquina braile. Outro impedimento para o funcionamento era que o recurso do FUNDEB não libera o pagamento para técnicos, então, de fato, as salas ficaram fechadas (MARLA RUNYA, PROFESSORA).

Qualquer política, por mais bem elaborada que seja, não vai adiante se não houver financiamento. O exemplo acima não é novidade na educação, vimos isso acontecer com os laboratórios de informática los infocentros), que foram enviados pelo MEC anos atrás. Pela falta de técnicos ou professores especializados para a operacionalização, muitos ficaram fechados e outros mal utilizados, até as máquinas se tornarem obsoletas.

Nesse contexto, o município estudado tem visto a implantação das salas de recursos multifuncionais como um grande desafio a ser cumprido, que exige organização, no que tange à declaração dos alunos no censo e elaboração de projetos pelas escolas, justificando a necessidade da sala, e mobilização política por parte da SEMEC. Segundo informações da secretaria e do CAEE, em 2018, foram revitalizadas duas salas de AEE e criadas outras três salas em diferentes escolas da rede municipal.

A respeito da estratégia 4.7/PME, que prevê a oferta de educação bilíngue, em Língua Brasileira de Sinais - LIBRAS aos (às) alunos (as) surdos e com deficiência auditiva [...], bem como a adoção do Sistema Braille de leitura para cegos [...] (ITAPETINGA, 2015), a SEMEC considera parcialmente cumprida.

Atualmente a rede possui 04 (quatro) alunos com deficiência auditiva, 01 (um) aluno com cegueira e 07 (sete) com baixa visão. Os quatro com deficiência auditiva recebem educação bilíngue no CAEE e têm intérprete; o aluno que tem cegueira é acompanhado por uma pedagoga especialista 
em deficiência visual desde 2016, em seu ambiente escolar, e, após a inauguração do CAEE, este passou a ter aulas do sistema Braille.

O intérprete tem acesso ao planejamento da aula com antecedência para se preparar com os vocábulos que ele desconhece. A adaptação curricular é feita pelo professor e, quando este não tem preparo, a psicopedagoga vai até a escola para dar o suporte. No AEE ensinamos a Língua Brasileira de Sinais LIBRAS e orientamos algumas atividades (VICENT VAN GOGH, INTÉRPRETE E PROFESSOR DE LIBRAS).

Em relação ao meu aluno que tem cegueira, eu o acompanho diariamente nas aulas. Como não veio livros adaptados para ele, os professores me passam o resumo dos conteúdos e as atividades, eu digitalizo e a máquina transforma em áudio e relevo. Eu tenho que receber esse material com antecedência para fazer as adaptações necessárias. É um trabalho de parceria. Já os alunos com baixa visão, eu acompanho da maneira que posso, pois cada um tem um laudo diferente e necessita de adaptações diferentes (MARA GABRILLE, PEDAGOGA, TRADUTORA E PROFESSORA DE AEE).

Esses relatos revelam que existe uma integração entre os professores das salas regulares e o apoio especializado. Embora saibamos que essa integração não acontece em todas as escolas, consideramo-la necessária e muito importante para a qualidade do atendimento oferecido, particularmente aos alunos com surdez, cegueira ou baixa visão.

Vygotsky (1993) destaca a importância da linguagem para o desenvolvimento humano, bem como da mediação entre professor e aluno para o alcance do nível de desenvolvimento potencial, ressaltando que essa mediação deve ser de qualidade, bem planejada, jamais empobrecida.

Portanto, cresce a necessidade de um trabalho conjunto entre os professores das salas regulares e apoio especializado, tanto para a elaboração de atividades mediadoras de qualidade, quanto para a valorização do aluno e adequado atendimento às suas necessidades.

\section{c) Oferta de profissionais de apoio especializado}

As estratégias 4.13 e 4.20/PME preveem a ampliação da equipe de profissionais da educação para atender a demanda do processo de escolarização dos (das) estudantes com deficiência [...] garantindo a oferta de profissionais de apoio ou auxiliares, tradutores (as) e intérpretes de Libras 
[...] (ITAPETINGA, 2015). Ambas foram consideradas pela SEMEC como totalmente cumpridas.

Com relação à primeira (4.13), os dados revelaram que essa avaliação não procede, pois a estratégia 4.13 garante também a oferta de professores de AEE. Como foi citado anteriormente, apenas cinco escolas oferecem esse serviço, além do CAEE, apesar da rede possuir um número expressivo de psicopedagogos, quase um por escola.

Diante disso, questiona-se: por que esses profissionais não são direcionados para o AEE e outros contratados, via concurso público, para assumirem suas aulas? Eles seriam os articuladores do processo inclusivo em cada escola, colaborando com a formação dos seus colegas e elaborando projetos para a aquisição das salas de recursos multifuncionais.

Baptista e Jesus (2009) destacam que são muitos os desafios enfrentados por qualquer município que busca implementar a PNEEPEI, e esses desafios perpassam barreiras atitudinais, científicas e principalmente políticas, provocando um abismo entre o real e o ideal.

Já em relação à segunda estratégia (4.20/PME), a avaliação está correta, pois atualmente todos os alunos com deficiência na rede municipal de Itapetinga, que necessitam de apoio específico de outros profissionais para desenvolverem-se em suas singularidades, possuem um auxiliar, chamado de 'cuidador', ou um intérprete de LIBRAS, ou um tradutor de Braille, conforme informações do CAEE:

Como a demanda de alunos com deficiência auditiva e alunos com deficiência visual é pequena, nossos profissionais tem dado conta. $E$, na medida em que vamos precisando de cuidador para algum aluno que tem direito e necessidade, a secretaria de educação tem nos atendido. É só a gente enviar um ofício solicitando e eles mandam imediatamente. Quanto a esse aspecto não há dificuldade ou desafio, a barreira é de outra ordem, por exemplo, a formação desses profissionais (FRIDA KAHLO, COORDENADORA DO CAEE).

Com referência à formação dos 'cuidadores', não há uma exigência na lei. A própria Nota Técnica No 19/ 2010/ MEC/ SEESP/ GAB, que trata de profissionais de apoio para pessoas com deficiência, não exige que eles sejam pedagogos ou que tenham alguma capacitação na área de 
educação especial, mas apenas alguém que possa cuidar da locomoção, das atividades da vida diária, como levar ao banheiro, lavar as mãos, comer. Aliás, o documento assevera que "não é atribuição do profissional de apoio desenvolver atividades educacionais diferenciadas, ao aluno públicoalvo da educação especial, e nem se responsabilizar pelo ensino deste aluno" (BRASIL, 2010).

A lei entende que o apoio pedagógico ao aluno com deficiência, Transtorno do Espectro Autismo (TEA) ou superdotação, realizado através do AEE, deve ser oferecido nas Salas de Recursos Multifuncionais (SRM), por profissionais especialistas, ou seja, cuidadores e pedagogos têm papéis bem distintos nesse processo.

Não concordamos com essa nota técnica, pois a função do profissional de apoio (cuidador) acaba não se restringindo aos cuidados básicos, é ele que fica ao lado dos alunos, ajudando-os na realização de todas as atividades propostas. Outro ponto a ser destacado é que nem toda escola possui sala de recursos multifuncionais e professores de AEE para a realização dessas atividades, portanto o ideal seria que os profissionais de apoio fossem educadores especializados em educação inclusiva e que fossem valorizados profissionalmente.

\section{d) Formação de professores}

Um dado que não trouxe surpresas para nossa pesquisa foi confirmar que uma das três estratégias não cumpridas é a 4.18/PME, que prevê firmar parcerias com o programa de governo da União e do Estado para garantir a formação continuada de professores em AEE [...] (ITAPETINGA, 2015). Em todas as falas, de forma unânime, os professores reclamam a falta de formação continuada, apesar de a SEMEC ter uma visão contrária:

Destacamos como avanço também ações de formação continuada que foram realizadas assiduamente nos últimos dois anos, com destaque para o Seminário de Educação com foco na Educação Inclusiva realizada em agosto de 2017 (JOHN NASH, SECRETÁRIO DE EDUCAÇÃO). 
Segundo os professores e profissionais entrevistados, houve um Seminário em agosto de 2017, com duração de um dia apenas. Esse tipo de formação contribui para fomentar discussões e provocar reflexões acerca da temática, porém, não são suficientes, são pontuais.

A SEMEC já realizou formações mais completas, só que foram direcionadas apenas aos professores de AEE. Os relatos abaixo ilustram os anseios dos professores, que não se sentem preparados para atuarem de forma inclusiva.

Nunca recebi formação na área de educação inclusiva desde que cheguei aqui. Tive que estudar/pesquisar (procurei por conta própria). A partir das orientações da psicopedagoga elaborarei um plano de ação para melhor atendimento a estes alunos [...] Foi difícil porque nós não conhecemos as várias deficiências, transtornos, entre outras necessidades. E para cada situação é um atendimento diferenciado. Tenho dois anos na escola e até o momento nunca foi oferecido aos profissionais nenhum tipo de formação. (EMANUELLE LABORIT, COORDENADORA PEDAGÓGICA).

A formação tem que ser continuada. Estamos com dificuldade de trabalhar com essas crianças, precisamos de ajuda, sozinhos não vamos cumprir com o nosso papel. E sem formação, sem a presença dos especialistas na escola (pelo menos uma vez no mês) todos saem perdendo. Nós, porque nos cansamos e nos sentimos culpados por não estarmos fazendo o trabalho que gostaríamos, e as crianças, por não se sentirem inclusas no ambiente escolar (OLGA IVANOVNA, PROFESSORA).

A preocupação com a formação continuada expressa no discurso dos professores revela-se quase um apelo daqueles que constantemente enfrentam os desafios do fazer pedagógico. Muitos destacaram que existem também professores que não se interessam pela formação, mesmo quando essa é oferecida, e não buscam os cursos gratuitos disponibilizados pela internet. Tais profissionais só perceberão a necessidade da formação quando receberem um aluno com deficiência em suas salas de aula.

Não queremos com essas reflexões remir as secretarias municipais e estaduais da obrigação com a formação continuada de seus professores, pelo contrário, concordamos com Mantoan e Pietro (2006, p. 63) quando asseveram que "os professores devem ser capacitados pelos respectivos 
sistemas públicos de ensino aos quais estão afiliados ou pela parceria dos mesmos com instituições formadoras de professores".

O que buscamos pontuar, portanto, é a necessidade de sairmos do discurso da queixa, do 'não me sinto preparado', que circula há mais de vinte anos, para o discurso da resistência, da luta contra a desvalorização da profissão docente, o qual "revela um professor militante, envolvido nas discussões da inclusão, que intervém e exige condições para que a inclusão aconteça" (MIRANDA, 2009, p. 216).

\section{e) Acessibilidade pedagógica}

Com referência à estratégia 4.19/PME, que prevê a elaboração e implementação de uma Proposta Pedagógica Curricular da rede municipal de ensino que assegure a Política de Educação Especial (ITAPETINGA, 2015), a SEMEC assume que seu cumprimento ainda não foi possível, não justificando o motivo ou apontando as dificuldades.

O conhecimento para Vygostky é produto da cultura humana e deriva da capacidade do homem de pensar abstratamente, assim, cabe à escola o papel de desenvolver na criança, especificamente aquelas que possuem alguma deficiência, funções psicológicas superiores que ampliarão essa capacidade de apreender e elaborar conceitos científicos. O foco deve ser, portanto, o que a criança é capaz de aprender a partir da mediação com o outro e não as suas limitações. Essa deve ser uma característica do currículo em si, aquele elaborado para todos os alunos, com ou sem deficiência.

Sobre isso, Mantoan (2008) ressalva que não deve existir um 'currículo adaptado' para a escola inclusiva, no sentido de suprimir conteúdos ou reduzir o nível de complexidade dos mesmos, mas uma proposta curricular pautada na compreensão da heterogeneidade, existente cada vez mais nas salas de aula, que subsidie metodologias diversificadas para que as crianças com deficiência aprendam os mesmos conteúdos dos colegas, cada um no seu ritmo e conforme suas possibilidades. 


\title{
f) Articulação com os setores público / privado / comunitário
}

Esta categoria absorve um número maior de estratégias: a 4.12, 4.14, $4.15,4.16,4.17$ e 4.21/PME. Todas preveem a promoção de parcerias com as secretarias de Saúde e de Ação Social, instituições públicas ou filantrópicas com o intuito de favorecer o atendimento aos alunos com deficiência, transtornos globais do desenvolvimento e altas habilidades ou superdotação (ITAPETINGA, 2015).

A estratégia 4.16/PME, que busca, através dessas parcerias, favorecer a participação das famílias e da sociedade na construção do sistema educacional inclusivo (ITAPETINGA, 2015) foi considerada parcialmente cumprida, já as demais foram avaliadas pela SEMEC como totalmente cumpridas:

\begin{abstract}
A Secretaria de Educação firmou parcerias profícuas com a Secretaria de Saúde e de Desenvolvimento Social a fim de garantir os direitos dos alunos e de suas famílias. Com a saúde foi possível realizar teste de acuidade visual, encaminhamentos para realização de consultas e exames clínicos. Já no âmbito do Desenvolvimento Social as ações foram no sentido de reduzir as vulnerabilidades das famílias, através dos encaminhamentos de alunos com deficiência para serem contemplados com $O$ BPC e demais benefícios socioassistenciais (JOHN NASH, SECRETÁRIO DE EDUCAÇÃO).

Uma das coisas que me deixa feliz é questão das parcerias, com a saúde, com a equipe do CREAS [...]. O que embarga na saúde? Alguns especialistas que faltam no município. [...] O município não oferece neuropediatra, nem psiquiatra infantil. Tem o neuro na APAE que já tem uma demanda imensa, mas que, ainda assim, quando a gente precisa acaba dando um jeitinho [...] (HELLEN KELLER, PSICOPEDAGOGA DA REDE).
\end{abstract}

Observa-se aqui certo distanciamento entre a fala do gestor e a realidade mostrada. As parcerias não parecem tão profícuas assim. Faltam especialistas 'parceiros' para atenderem à demanda apresentada pelo CAEE, levando-os a dependerem do 'jeitinho' que às vezes precisa ser dado pela APAE.

O estabelecimento dessas parcerias é muito importante para a transformação da escola em um ambiente inclusivo. Sendo assim, torna-se fundamental compreender como essas alianças são construídas, ou a falta 
delas, para o fortalecimento dos laços entre a escola e a comunidade a qual pertence.

\section{g) Parceria com a universidade (apoio, pesquisa e assessoria)}

As estratégias 4.5, 4.10 e 4.11/PME preveem o estabelecimento de parcerias com as instituições de ensino superior com foco na promoção e desenvolvimento de pesquisas, e ações interdisciplinares de apoio e assessoria voltadas para o desenvolvimento de metodologias, materiais didáticos, equipamentos e recursos de tecnologia assistiva, com vistas à promoção do ensino e da aprendizagem dos alunos com deficiência, transtornos globais do desenvolvimento e altas habilidades ou superdotação (ITAPETINGA, 2015). Todas consideradas parcialmente cumpridas pela SEMEC.

Segundo os professores entrevistados, as escolas deveriam abrir mais espaço para os estudantes que estão em processo de formação e a universidade poderia atuar de forma mais consistente, através dos estágios supervisionados ou de projetos de extensão que envolvessem discentes de pedagogia e professores da rede municipal na construção de práticas pedagógicas inclusivas.

A parceria com a Universidade Estadual do Sudoeste da Bahia (UESB) firmada através do Programa Institucional de Bolsa de Iniciação à Docência (PIBID) subprojeto de Educação Especial trouxe muitos ganhos para as escolas contempladas com o programa durante o período em que o mesmo funcionou. Esse diálogo entre escola e universidade é importantíssimo e deveria ser constante, haja vista que é função social da universidade promover atividades de extensão que beneficiem a comunidade em que ela está inserida.

Após a descrição das ações realizadas pela SEMEC de Itapetinga, consideradas como pequenos, mas, significativos avanços em prol da implementação da PNEEPEl, bem como de uma síntese avaliativa do cumprimento da Meta 4/PME, apresentamos, à guisa de conclusão, alguns 
desafios que, na visão da Secretaria de Educação, estão obstacularizando a implementação da política.

\begin{abstract}
São vários os desafios, mais dois são mais emergentes. O primeiro é de ordem financeira. É necessário aporte de recursos para implementação da política. Nos últimos anos temos vivido uma inversão do pacto federativo, os municípios estão cada vez mais sobrecarregados de obrigações sem o necessário apoio do governo federal, além de enfrentar uma grave crise financeira que impede ações mais arrojadas. O segundo desafio está relacionado ao entendimento da Política de Educação Especial por parte dos profissionais da educação. Existe uma confusão na definição dos conceitos básicos da Política. Por exemplo, a patologização do aluno, a criação de modelos ideais de crianças ou ainda a negação de direitos aos estudantes (JOHN NASH, SECRETÁRIO DE EDUCAÇÃO).
\end{abstract}

$\mathrm{Na}$ visão dos professores e demais profissionais de apoio, os desafios perpassam pelas barreiras conceituais, políticas, econômicas e atitudinais. Eles destacam também a formação continuada como primeiro passo para a transformação da escola em um ambiente, no qual a diversidade humana seja valorizada, uma escola que assuma "uma postura de desconstrutora de igualdades, visando incluir na tessitura social àqueles que vêm sendo sistematicamente excluídos" (JESUS, 2006, p. 97).

Nesse sentido, e concordando com Jesus (2006, p. 97), concluímos que os discursos e ações dos professores devem ser valorizados, pois são eles que, "entre medos, dúvidas, ansiedades, disponibilidades, acolhimentos e possibilidades, recebem os alunos em suas salas de aula" e buscam desenvolver práticas pedagógicas que se aproximem, pelo menos em parte, dos princípios da educação inclusiva.

\title{
CONSIDERAÇÕES FINAIS
}

O estudo realizado permitiu constatar que, a despeito da implementação da PNEEPEI no município de Itapetinga, as proposições político-pedagógicas realizadas até o momento revelam pequenos, mas, significativos avanços na construção de um sistema de ensino inclusivo, dentre elas destaca-se a implantação do Centro de Atendimento Educacional Especializado (CAEE), em dezembro de 2017, e a instalação de cinco salas de recursos multifuncionais, em 2018. 
Nos limites da investigação ora empreendida, os dados utilizados foram substanciais para evidenciar um crescimento de $214,9 \%$ nas matrículas de alunos público-alvo da Educação Especial nas classes regulares de ensino, entre período de 2015 a 2018, saindo de 154 alunos para 485 alunos matriculados. Apesar de ser um número expressivo, sabemos que é preciso muito mais do que o acesso e permanência nas classes regulares para que a inclusão aconteça de fato.

Conforme os dados obtidos, ficou evidenciada a necessidade de formação continuada, com vista ao desenvolvimento de propostas inclusivas de ensino para os professores, tanto aqueles que estão nas classes regulares, quanto os professores de AEE.

Consoante aos princípios da PNEEPEI, Miranda (2009, p. 210) reitera que a construção de uma escola inclusiva não depende só da formação dos professores e mudanças em suas práticas educativas, mas também da eliminação dessas barreiras que interferem no atendimento ao aluno. 0 desafio, portanto, está em romper com a visão de que está nas mãos do professor, juntamente com os profissionais especializados, a responsabilidade pela aprendizagem e desenvolvimento dos alunos com deficiência. Até porque, além de ser uma visão romântica (BEZERRA, 2016), ela contribui para a perpetuação da lógica neoliberal que desresponsabiliza o Estado de suas obrigações.

Diante das constatações possíveis neste momento, reconhecemos que os desafios para a SEMEC de Itapetinga ainda são inúmeros, que é preciso priorizar algumas ações, dentre elas: promover a formação continuada de todos os professores, não só dos que trabalham com o AEE; ampliar o número de profissionais para atuarem no CAEE e nas Salas de Recursos Multifuncionais (SRM); assessorar os gestores na construção de projetos que viabilizem a vinda de recursos do MEC para montagem de novas salas de recursos; e, principalmente, não se acomodar, acreditando que as ações realizadas até então são grandes feitos desta gestão e, por isso podem ser consideradas suficientes para elevar a educação do município ao patamar de educação inclusiva. 
Para os professores, os desafios não são menores, deve-se vencer em primeiro plano as barreiras atitudinais, pois são elas que limitam a descoberta e elaboração de novas práticas educativas, menos assistencialistas e mais mediadoras, menos individualistas e mais coletivas, menos idealistas e mais crítico/reflexivas. Essas barreiras se configuram em resistência às mudanças oriundas dos processos inclusivos, até mesmo de acolher o aluno e aprender a trabalhar com e na diversidade.

Vencendo tais barreiras atitudinais, o professor que acredita na construção de uma escola inclusiva alimenta outras formas de resistência: resistência às ações reprodutoras de desigualdade e de exclusão; ao conformismo das "reformas paliativas" e arranjos inclusivos, tampouco às aparências sedutoras do discurso dominante (BEZERRA, 2016, p. 60); e, a qualquer ação do poder público que signifique retrocesso às conquistas adquiridas e ameaça ao direito inalienável das pessoas com deficiência ou outras singularidades de estarem numa classe regular e aprenderem, numa perspectiva inclusiva, os conteúdos disponibilizados a todos os alunos.

\section{REFERÊNCIAS}

BAPTISTA, C. R.; JESUS, D. M. de. (Orgs.). Avanços em Políticas de Inclusão: O contexto da Educação Especial no Brasil e em outros países. Porto Alegre: Mediação, 2009.

BEZERRA, F. G.; ARAÚJO, D. A. de C. As aparências enganam: a pretexto de uma crítica radical sobre o ideário inclusivista. Revista de Educação. v. 5 n. 9 jan./jun. p. 253-266, 2010.

BRASIL. Nota Técnica 19/2010 - MEC/SEESP/GAB. Dispõe sobre os profissionais de apoio para alunos com deficiência e TGD. Disponível em:

<https://inclusaoja.com.br/tag/nota-tecnica/> Acesso em 20 jul. 2018.

BRASIL, Ministério da Educação. Secretaria de Educação Continuada, Alfabetização, Diversidade e Inclusão - SECADI. A consolidação da inclusão escolar no Brasil 2003 a 2016. Brasília, 2016.

CAIADO, K. R. M.; LAPLANE, A. L. F. de. Tramas e redes na construção de uma política municipal de educação inclusiva. In: BAPTISTA, C. R.; JESUS, D. M. de. (Orgs.) Avanços em políticas de inclusão: o contexto da educação especial no Brasil e em outros países. Porto Alegre: Mediação, 2009. 
CEREZUELA, C. Política nacional de educação inclusiva: um estudo sobre sua efetivação nas cinco regiões brasileiras. 2016. 240 p. Tese (Doutorado em Educação) - Universidade Estadual de Maringá. Maringá, 2016.

CORTELLA, M. S. A escola e o conhecimento: fundamentos epistemológicos e políticos. São Paulo: Cortez, 1998.

CROCHIK, J. L. Educação Inclusiva, subjetividade, preconceito e direitos humanos. In: SILVA, A. M. M.; COSTA, V. A. da. (Orgs.). Educação Inclusiva e Direitos Humanos: perspectivas contemporâneas. São Paulo: Cortez, 2015. p. 23-53.

ITAPETINGA- BA. Secretaria Municipal de Educação e Cultura. Plano Municipal de Educação: desafios e perspectivas para a nova década. Itapetinga-BA, 2015. 122 p.

JESUS, D. M. de. Inclusão Escolar, formação continuada e pesquisa colaborativa. In: BAPTISTA, C. R. (Org.) Inclusão e escolarização: múltiplas perspectivas. Porto Alegre: Mediação, 2006. p. 95-106.

KASSAR, M. de C. M. Percursos da constituição de uma política brasileira de educação especial inclusiva. Revista Brasileira de Educação Especial. Marilia, SP, v. 17, n. spel, p. 41-58, Ago., 2011.

MANTOAN, M. T. E.; PIETRO, G. R. Inclusão Escolar: pontos e contrapontos. São Paulo: Summus, 2006.

MANTOAN, M. T. E. Colóquio: Política Nacional de Educação Especial na Perspectiva da Educação Inclusiva. Inclusão: Revista da Educação

Especial/Secretaria da Educação Especial. v. 4, n.1, p. 18-32, jan./jun. 2008.

MENDES, E. G. Inclusão: é possível começar pela creche? In: $29^{a}$ Reunião Anual da ANPED, Caxambu, MG, 15-18 out. 2012.

MÉSZAROS, I. Para além do Capital. São Paulo: Boitempo, 2002.

MIRANDA, T. G. Gestão da educação em atenção às necessidades especiais: entre o discurso oficial e o discurso do professor. In: BAPTISTA, C. R.; JESUS, D. M. de; (Orgs) Avanços em políticas de inclusão: o contexto da educação especial no Brasil e em outros países. Porto Alegre: Mediação, 2009.

SAVIANI, D. Transformações do capitalismo, do mundo do trabalho e da educação. In: LOMBARDI, J. C.; SAVIANI, D.; SANFELICE, J. L. (Org.). Capitalismo, trabalho e educação. 3. ed. Campinas: Autores Associados; Histedbr, 2005. p. 13-24.

VYGOTSKY, L. S. Pensamento e Linguagem. São Paulo: Martins Fontes, 1993. 
VYGOTSKY, L. S. A formação social da mente: o desenvolvimento dos processos psicológicos superiores. Trad. de José C. Neto, Luís S. M. Barreto, Solange C. Afeche. 6. ed. São Paulo: Martins Fontes, 1998.

Recebido em: 16 de julho de 2019 Aprovado em: 10 de setembro de 2019 